\title{
EDITORIAL
}

\section{MÁSCARAS UTILIZADAS PELOS PROFISSIONAIS DA SAÚDE: O QUE É RECOMENDADO?}

\author{
Helenize Ferreira Lima Leachi ${ }^{1}$, Renata Perfeito Ribeiro ${ }^{2}$
}

Autor(a) correspondente: Helenize Ferreira Lima Leachi. Av.: Robert Koch, 60 -Vila Operária, Londrina - PR, CEP 86038-350. Fone (43) 33712249. E-mail: nizeflima@hotmail.com

\section{Como citar esse artigo}

Leachi H. F. L.; Ribeiro R. P. Máscaras utilizadas pelos profissionais da saúde: o que é recomendado?. Advances in Nursing and Health [Internet]. 2020; 2(1): 2-7.

Em dezembro de 2019, a Organização Mundial da Saúde (OMS), foi alertada sobre o surgimento de uma nova cepa de coronavírus (SARS-CoV-2) na China, não identificada até aquele momento em seres humanos, o qual causava quadros de doença respiratória aguda grave (COVID-19). Desde então, o número de pessoas afetadas por essa doença, tem aumentado substancialmente.

No final de janeiro de 2020, a OMS declarou que o surto desse vírus, consistia em uma Emergência de Saúde Pública de importância Internacional e em março, esta doença, foi declarada como uma Pandemia(1).

Como não existem vacinas e medicamentos específicos disponíveis para o tratamento dessa doença, medidas foram implementadas com a finalidade de diminuir a propagação da infecção. Entre essas medidas estão o controle ambiental como a higiene e a desinfecção, detecção e notificação dos casos de forma precoce, distanciamento

\footnotetext{
${ }^{1}$ Mestre. Doutoranda do Programa de Pós-Graduação em Enfermagem da Universidade estadual de Londrina. ORCID ID: https//orcid.org/0000-0002-7792-3407

2Doutora. Docente do Programa de Pós-Graduação em Enfermagem da Universidade Estadual de Londrina. ORCID ID HTTPS//orcid.org/0000-0002-7821-9980
} 
social, isolamento e quarentena e o uso de Equipamentos de Proteção Individual (EPI) nos serviços de saúde1. Entre os EPI a serem utilizados, estão as máscaras e os respiradores faciais.

Existem vários tipos de máscaras: cirúrgica, $\mathrm{N} 95, \mathrm{PFF}^{3 *}, \mathrm{PFF} 2^{4^{* *}}, \mathrm{PFF} 1^{5^{* * *}}$, entre outras, sendo classificadas em dois tipos: de resistência ao aerossol, tipo $S$, que retém partículas sólidas e líquidas a base de água, e tipo SL, que retém partículas sólidas e líquidas a base de água e óleo.

As máscaras de filtro PFF2 e PFF3 são utilizadas para proteção de agentes biológicos em forma de aerossóis e também são máscaras resistentes à projeção de fluidos corpóreos. Já as máscaras de filtro PFF1 não são recomendadas para o uso contra agentes biológicos, pois os filtros protegem apenas contra presença de partículas sólidas como poeiras ou névoas não oleosas. A N95, é uma classificação de filtro para aerossóis adotada pelas agências americanas e que equivale ao filtro PFF2(2).
As principais agências nacionais e internacionais de saúde concordam que as máscaras e respiradores faciais servem para a proteção do profissional de saúde, porém, existem algumas diferenças no que é preconizado por cada uma dessas agências, em relação ao uso dessas medidas de proteção.

Portanto, neste momento, retiraremos dúvidas em relação às máscaras e respiradores faciais utilizados por profissionais da área da saúde, durante as suas atividades laborais. Reiteramos que o seu uso não se faz diferente em épocas onde não existem pandemias como a do COVID-19.

A máscara cirúrgica é uma barreira de uso individual que cobre o nariz e a boca, porém, é frouxa na face e não protege o profissional de inalar aerossóis ambientais. Ela foi projetada para diminuir a contaminação do ambiente das secreções respiratórias geradas pelopaciente que ali se encontra e também, proteger o trabalhador da inalação de gotículas ou outros fluídos corpóreos, trans-

\footnotetext{
${ }^{3 *}$ Penetração máxima permitida na peça semifacial filtrante PFF3 - 1\%

${ }^{4 * *}$ Penetração máxima permitida na peça semifacial filtrante PFF2 - 6\%

${ }^{5 * * *}$ Penetração máxima permitida na peça semifacial filtrante PFF1 - 20\%
} 
mitidos numa curta distância e que possam atingir as suas vias respiratórias ${ }^{(3-4)}$.

A OMS preconiza o uso da máscara cirúrgica para procedimentos de rotina, e a mesma, deve ser trocada sempre que apresentar sujidades e umidade ${ }^{(1)}$.

As máscaras N95 e PFF2 são EPI também chamados de respiradores, utilizados para diminuir o risco ocupacional do trabaIhador, cobrindo a boca e o nariz, com vedação adequada à face do usuário. Além disso, esses respiradores possuem um filtro capaz de reduzir o risco de inalação de partículas contendo vírus, bactérias ou fungos, através da retenção desses contaminantes, pela exposição do usuário a gotículas ou aerossóis(3)

Os respiradores N95 e PFF2 apresentam nível equivalente de proteção. Os classificados como PFF2 seguem a norma brasileira e a europeia e os classificados como N95, seguem a norma americana. Ambos, apresentam filtração mínima de $95 \%^{(3-5)}$.

Os respiradores com válvulas, também possuem o mesmo nível de proteção daqueles que não as possuem. A diferença entre eles, é que, a presença da válvula reduz a resistência à expiração facilitando a respiração, porém, esses respiradores não são indicados para procedimentos cirúrgicos, procedimen- tos estéreis e também quando os profissionais estão expostos a alta geração de fluidos corporais $^{(5)}$

A OMS e outras agências, preconizam o uso dos respiradores N95 e PFF2, em caso de procedimentos que gerem aerossóis ${ }^{(1-8)}$.

Por outro lado, agências americanas ${ }^{(5,9)}$ recomendam, o uso de respiradores faciais para todos os procedimentos de rotina $\mathrm{e}$ também em situações de alto risco, como no caso de pacientes portadores de COVID-19. As diretrizes inglesas ${ }^{(10)}$, recomendam o uso do respirador PFF3 em caso de procedimentos que gerem aerossóis.

Em relação ao uso único ou reutilização de respiradores, o Centro de Controle e Prevenção de Doenças dos Estados Unidos afirma que, a reutilização dos respiradores, onde ele é removido e recolocado a cada atendimento, pode resultar em risco de transmissão de infecção por contato, quando o usuário toca a superfície contaminada do respirador, sem perceber que realizou esta prática. O uso prolongado é mais favorecido em relação à sua reutilização, devido ao menor risco de toque no respirador ${ }^{(5)}$.

O uso prolongado do respirador por até 8 horas, pode ser mais seguro do que guardá-lo após o uso e depois reutilizá-lo, pois, 
a funcionalidade do respirador depende de variáveis que devem ser avaliadas em relação à: danos, perfurações, elásticos preservados, umidade e presença de fluidos corpóreos. Além disso, quando a respiração estiver dificultada com a presença do respirador, a mesma pode estar contaminada(5), devendo portanto, ser descartada.

Essa avaliação é difícil de ser realizada de forma padronizada por todos usuários, quando da reutilização desses respiradores faciais.

Se a opção for por reutilizar o respirador, a equipe deve receber treinamento de práticas necessárias para minimizar o risco de transmissão de contaminação. Entre essas práticas, podemos citar: a utilização de uma máscara cirúrgica por cima do respirador facial para reduzir a contaminação do mesmo, a armazenagem do respirador em recipiente que possa ser identificado, higienizado ou descartado e nunca tocar a parte de dentro do respirador ${ }^{(5)}$.

Importante lembrar que, a máscara cirúrgica nunca deve ser usada por baixo dos respiradores faciais, pois impede a vedação correta do respirador facial ao rosto do usuário e a máscara cirúrgica usada em cima do respirador facial, deve ser descartada a cada uso e ao apresentar sinais de umidade ou sujidade.

Todas essas questões são importantes para que os respiradores se adequem ao rosto dos usuários de maneira correta e sejam seguros para o uso dos trabalhadores.

Assim, os profissionais da saúde que atuam diretamente no cuidado de pacientes portadores ou não de doença infectocontagiosa, devem fazer uso adequado de paramentação e máscara para o momento, evitando a transmissão e a autocontaminação.

Além de que, o uso racional do EPI é uma prática que deve ser adotada por todos os usuários. Para isso, não somente em épocas difíceis de pandemias, todas as instituições de saúde devem utilizar-se de protocolos de proteção respiratória e treinamentos sobre paramentação e desparamentação, quando existe a necessidade do uso de EPI.

Estas ações proporcionam maior segurança ocupacional aos profissionais de saúde, e também, uma assistência de qualidade aos clientes assistidos. 


\section{REFERÊNCIAS}

1. World Health Organization (WHO). Novel Coronavirus (2019-nCoV) (2020). Disponível em: https://www.who.int/westernpacific/ emergencies/novel-coronavirus.

2. Brasil. Agência Nacional de Vigilância Sanitária. Cartilha de proteção respiratória contra agentes biológicos para trabalhadores de saúde. (Junho de 2015).

3. Brasil. Nota técnica 04/2020. Agência Nacional de Vigilância Sanitária. (31 de março de 2020). Disponível em: http://portal. anvisa.gov.br/documents/33852/271858/ Nota + T\%C3\%A9cnica $+n+04-2020+$ GVIMSGGTES-ANVISA/ab598660-3de4-4f14-8e6fb9341c196b28.

4. He X, ReponenT, McKay RT, Grinshpun SA. Effect of Particle Size on the Performance of an N95 Filtering Facepiece Respirator and a Surgical Maskat Various Breathing Conditions. Aerosol Science and Technology, v.47, n.11, p. 1180-1187, 2013. DOI:10.1080/02786826 .2013 .829209 .

5. Center for Disease Control and Prevention (CDC) Interim Healthcare Infection Prevention and Control Recommendations For Patients Under Investigation for 2019 Novel Coronavirus (2020). (Janeirode2020). Disponível em: https://www.cdc.gov/coronavirus/2019nCoV/infection-control.html e https:// www.cdc.gov/coronavirus/2019-ncov/ hcp/respirators-strategy/crisis-alternatestrategies.html.

6. Brasil, ministério da saúde. Procedimento Operacional Padronizado. Equipamento de proteção individual e segurança no trabalho para profissionais de saúde da aps no atendimento às pessoas com suspeita ou infecção pelo novo coronavírus (COVID-19).(Março de 2020) Disponível em: http://189.28.128.100/dab/docs/portaldab/ documentos/POP_EPI_APS_20200319_ ver001.pdf

7. Australian government departament of Health - CDNA National guidelines for public health units. Disponível em: https://www1.health. gov.au/internet/main/publishing.nsf/Content/ cdna-song-novel-coronavirus.html.

8. Government of Canadá - Coronavirus disease (COVID-19): For health Professional. (Março de 2020). Disponível em: https:// www.canada.ca/en/public-health/services/ diseases/2019-novel-coronavirus-infection/ health-professionals.html.

9. European Centre for Disease Prevention and Control. Infection prevention and control for the care of patients with 2019-nCoV in healthcare settings. (Fevereiro de 2020). Disponível em: https://www.ecdc.europa. eu/sites/default/files/documents/novecoronavirus-infection-prevention-control- 
patients-healthcare-settings.pdf.

10. Public Health England. Guidance. COVID-19: Infection Prevention and Control. (Março de 2020). Disponível em: https://www. gov.uk/government/publications/wuhannovel-coronavirus-infection-prevention-andcontrol/wuhan-novel-coronavirus-wn-covinfection-prevention-and-control-guidance.

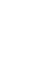

